\title{
The fish-hook configuration of the distal ureter indicates bladder outlet obstruction due to benign prostatic hyperplasia
}

\author{
Charalampos Mamoulakis • Thomas R. W. Herrmann • \\ Klaus Höfner • Matthias Oelke
}

Received: 23 August 2010/ Accepted: 30 October 2010/Published online: 16 November 2010

(C) The Author(s) 2010. This article is published with open access at Springerlink.com

\begin{abstract}
Purpose The aim of this retrospective study was to evaluate in a historical series of patients whether morphological changes of the urinary tract imaged on intravenous urography (IVU) are associated with clinical or urodynamic data.

Methods During a 1-year period, every man 45 years or older with lower urinary tract symptoms suggestive of benign prostatic hyperplasia was systematically evaluated with multi-channel computer-urodynamic investigation and IVU. Men with urinary retention, known bladder stones or diverticula, severely impaired renal function, or allergy to iodine contrast media were excluded. Structural alterations of the urinary tract were correlated with clinical and urodynamic data using logistic regression analysis.

Results Data on 203 consecutive patients were available for analysis. Multivariate analysis demonstrated that the "fish-hook" configuration of the distal ureter (also known as "hockey-stick", or "J-shaped" ureter) was the only sign significantly associated with benign prostatic obstruction (BPO) (odds-ratio 3.64; 95\% confidence interval 1.69-7.83; $P<0.001$ ). The sensitivity, specificity, positive and negative predictive values of the "fish-hook" ureter
\end{abstract}

C. Mamoulakis

Department of Urology, University of Crete Medical School, Heraklion, Crete, Greece

T. R. W. Herrmann · K. Höfner · M. Oelke $(\bowtie)$

Department of Urology, Hannover Medical School,

Carl-Neuberg-Str. 1, 30625 Hannover, Germany

e-mail: oelke.matthias@mh-hannover.de

K. Höfner

Department of Urology, Evangelic Hospital,

Oberhausen, Germany configuration sign to detect BPO was 53, 76, 61 and 70\%, respectively. Bladder trabeculation, upper urinary tract dilatation, or bladder base elevation were not associated with BPO, detrusor overactivity, detrusor underactivity, bladder low-compliance or any clinical data.

Conclusions The "fish-hook" shape of the distal ureter(s) indicates BPO and may be a result of prostate median lobe enlargement.

Keywords Benign prostatic hyperplasia - Bladder outlet obstruction · Fish-hook ureter - Intravenous urography . Lower urinary tract symptoms - Sensitivity $\cdot$ Specificity . Urodynamic investigation

\begin{tabular}{|c|c|}
\hline \multicolumn{2}{|c|}{ Abbreviations } \\
\hline BPH & Benign prostatic hyperplasia \\
\hline BPO & Benign prostatic obstruction \\
\hline BPE & Benign prostatic enlargement \\
\hline CI & Confidence interval \\
\hline IPP & Intravesical prostatic protrusion \\
\hline IPSS & International prostate symptom score \\
\hline IVU & Intravenous urography \\
\hline LUTS & Lower urinary tract symptoms \\
\hline OR & Odds ratio \\
\hline PVR & Post-void residual urine \\
\hline TRUS & Transrectal ultrasound \\
\hline UDI & Urodynamic investigation \\
\hline
\end{tabular}

\section{Introduction}

Benign prostatic hyperplasia (BPH) is the term used to describe the growth of epithelial, muscular and/or fibrotic 
cells in the prostate [1]. BPH may be associated with benign prostatic enlargement (BPE), lower urinary tract symptoms (LUTS) and benign prostatic obstruction (BPO), although no clear correlations among the components have been found so far [2-5]. BPH starts affecting men by their fourth decade and occurs in up to $90 \%$ in the ninth decade [6]. It is ranked fifth among the ten most frequently treated diseases in Western countries [7] and responsible for a high socio-economic burden in ageing societies.

Intravenous urography (IVU) is a radiological tool for the assessment of BPH-related changes of the upper/lower urinary tract (e.g. hydronephrosis, trabeculation, diverticula and bladder stones) and other urological diseases (e.g. nephro-/ureterolithiasis and upper urinary tract tumours). Despite its excellent diagnostic value, IVU was abandoned for routine work-up of patients with BPH in most Western countries in 1990s due to increased radiation risks, costs, and low additional diagnostic benefit compared to ultrasonography [8-11]. Nevertheless, IVU remains a valid tool to evaluate upper urinary tract pathology (stones, tumours) and haematuria until today. Therefore, physicians must still be familiar with IVU to properly judge the urinary tract.

This study aims to retrospectively investigate clinical and urodynamic data in a cohort of BPH-LUTS patients and correlate them with IVU signs to evaluate a potential association with morphological changes of the urinary tract in an attempt to contribute to the pathophysiology of the disease.

\section{Materials and methods}

\section{Inclusion and exclusion criteria}

During 1st January and 31st December 1994, all men aged $\geq 45$ years with BPH-LUTS referred to the Department of Urology, Hannover Medical School were systematically investigated according to the department policy with (a) medical history focusing on LUTS, (b) physical (digitorectal) examination, (c) International Prostate Symptom Score (IPSS), (d) urinalysis, (e) laboratory tests including prostate specific antigen and creatinine levels, (f) transrectal prostate ultrasound (TRUS), (g) free uroflowmetry and measurement of postvoid residual (PVR) urine, (h) multi-channel computer-urodynamic investigation (UDI), and (i) intravenous urography (IVU).

Men with an indwelling bladder catheter, impaired renal function (serum-creatinine $>180 \mu \mathrm{mol} / \mathrm{l}$ ), known bladder stones/diverticula, or allergy to iodine contrast media received a reduced work-up (a-f). Men with a neurological deficit, previous lower urinary tract or pelvis operations, known prostate or transitional cell cancer, or $5 \alpha$-reductase inhibitors were excluded. Only men with a complete workup $(\mathrm{a}-\mathrm{i})$ were included in the study.
Assessment protocol

All investigations were performed as outpatient procedures during two visits. Medical history, physical examination, urine as well as blood samples were taken. TRUS was performed with a $7.5 \mathrm{MHz}$ array and prostate volume was determined by measuring the greatest transverse and longitudinal dimensions. Free uroflowmetry was done when the patient reported a full bladder; a minimal voided urine volume of $150 \mathrm{ml}$ was considered acceptable to judge maximum urinary flow rate $\left(Q_{\max }\right)$. PVR was measured immediately after voiding using a $3.5 \mathrm{MHz}$ ultrasound array measuring the greatest bladder transverse and longitudinal distances. Free uroflowmetry and PVR measurements were repeated at least once and the highest $Q_{\max } /$ lowest PVR were used for analysis. Patients were asked to complete the IPSS questionnaire and deliver their answers at the second visit.

IVU and UDI were performed one to 3 weeks after initial presentation if renal function and urinalysis were appropriate. Three IVU images were taken in the lying position; the first before and the second and third five and 15 min after contrast media infusion $\left(100 \mathrm{ml} \mathrm{Solutrast}^{\mathrm{TM}}\right.$ 300 ), respectively. UDI was performed using a $7 \mathrm{~F}$ transurethral microtip and a $12 \mathrm{~F}$ rectal catheter. The bladder was filled with physiological saline solution of $37^{\circ} \mathrm{C}$ at a rate of $25-50 \mathrm{ml} / \mathrm{min}$. Methods, definitions and units were in line with the International Continence Society recommendations [1]. UDI were conducted at least twice and the lowest degree of BPO, based on the Schäfer classification [12], was used for analysis.

Evaluation of morphological and functional signs

Structural alterations of the urinary tract on IVU were correlated with clinical and urodynamic data using logistic regression analysis. We focused on the following binary dependent variables based on IVU findings (Fig. 1): (a) urinary tract calcifications, (b) delayed excretion of contrast media, (c) upper urinary tract dilatation of any degree, (d) peristalsis of the ureter(s), (e) uni- or bilateral "fishhook" configuration of the distal ureter ("hockey-stick" or "J-shaped" ureter), (f) delayed emptying of the ureter(s), (g) bladder base elevation of any degree, (h) bladder diverticula unknown prior to investigation and/or trabeculation.

The following urodynamic variables were tested as potential predictors of the dependent variables (univariable analysis): (a) normal/low bladder compliance, (b) presence/ absence of detrusor overactivity, (c) amplitude of uninhibited detrusor contractions in patients with detrusor overactivity, (d) presence/absence of detrusor overactivity incontinence, (e) normal/week detrusor work during 

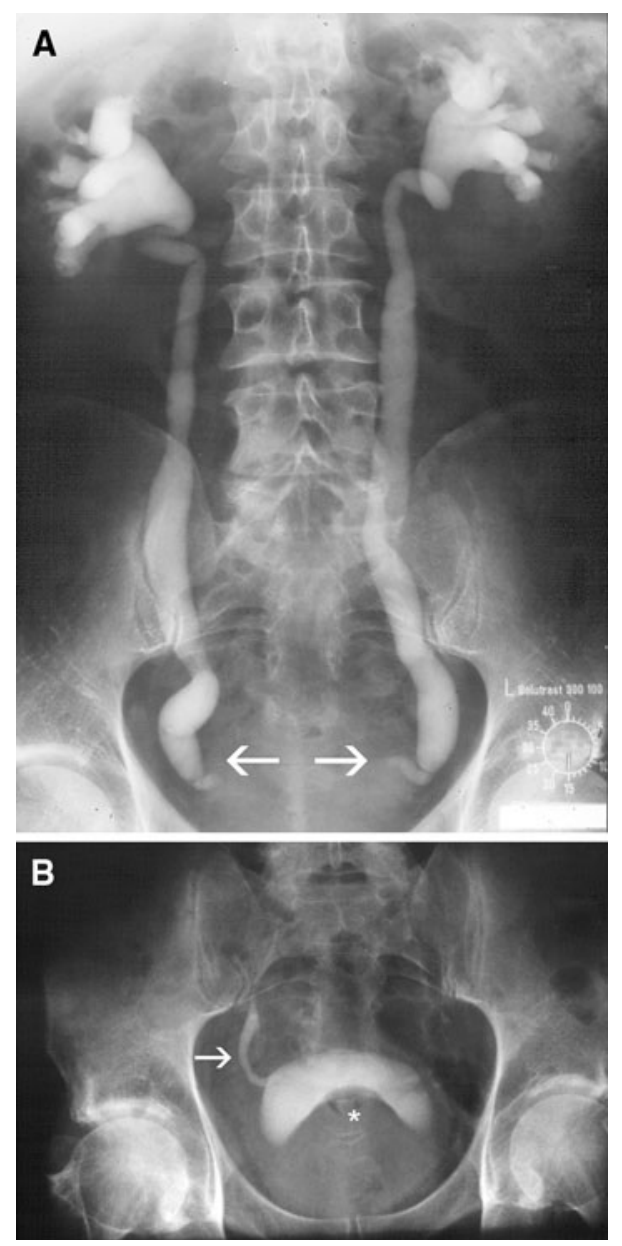

Fig. 1 Intravenous urography imaging the urinary tract $15 \mathrm{~min}$ after contrast media infusion showing bilateral "fish-hook" ureters $(\rightarrow)$ and hydronephrosis in an 64-year old men with BPH-LUTS (a) as well as a unilateral "fish-hook" ureter $(\rightarrow)$ and elevated bladder base (*) in an 70-year old man with BPH-LUTS (b)

voiding (DAMPF [12]), (f) presence/absence of BPO (Schäfer nomogram). Significant predictors detected were further evaluated after adjusting for possible confounding patient characteristics, namely age, prostate volume, PVR and bladder capacity at UDI.

\section{Results}

Data on 203 men were available for analysis. General patient characteristics and the number of patients with the specific IVU or urodynamic findings are summarized in Table 1. Univariable binary logistic regression analysis revealed

- presence of stones was significantly associated with low bladder compliance (OR 3.84, 95\% CI: 1.29-11.43; $P=0.016)$,

- elevation of the bladder base was significantly associated with BPO (OR 2.01, 95\% CI: 1.14-3.54; $P=0.016$ ),
- "fish-hooked" configuration of the distal ureter(s) was significantly associated with BPO (OR 3.59, 95\% CI: 1.96-6.57; $P<0.001)$.

When potential confounding variables (age, prostate volume, PVR, and bladder capacity) were taken into account in the respective multivariate regression models to test the aforementioned significant associations, only the association between the "fish-hook" ureter(s) and BPO remained significant (Table 2; models for stones and bladder base elevation with insignificant findings not shown). Based on the multivariate regression model, BPO was the only independent predictor of "fish-hook" ureters.

The sensitivity, specificity, positive and negative predictive values of "fish-hook" ureter(s) to diagnose BPO was 53, 76, 61 and 70\%, respectively, resulting in an overall test accuracy of $67 \%$. The likelihood ratio of a positive test result was 2.22 (95\% CI 1.51-3.24; Table 3).

Table 4 demonstrates the general characteristics of patients with or without the "fish-hook" sign of the distal ureter(s) indicating a significantly greater prostate volume and higher serum PSA level in the former subgroup.

\section{Discussion}

We investigated in a historical group of unselected patients with BPH-LUTS the relationship between morphological and functional signs of the urinary tract, determined by IVU and UDI, respectively. The "fish-hook" shape of the distal ureter(s) was found to be significantly associated with BPO. To the best of our knowledge, we present for the first time urodynamic evidence for this association. The "fish-hook" ureter has been described in many urological textbooks [13-15] and was regarded as a sign of BPE $[16,17]$.

According to the department policy, every man with BPH-LUTS was investigated with the identical assessment protocol in 1994. Only patients with other possible causes of LUTS and those unsuitable for IVU or UDI were excluded. Men with known bladder stones, diverticula, or urinary retention were deprived of UDI because they were considered obstructed [18] and were submitted directly to prostate surgery. Consequently, our study group consisted of 203 consecutive patients who were able to void and considered to have uncomplicated BPH-LUTS. Inclusion of more patients might have resulted in selection bias, because UDI was incomplete during 1991-1993 and IVU for the routine assessment of patients with BPH-LUTS was rarely performed in 1995 and finally abandoned in our department in 1996. A similar study today using IVU or CT imaging does not seem to be ethically justified due to the 
Table 1 General patient characteristics (A) and findings on intravenous urography (B) or computer-urodynamic investigation $(\mathrm{C})$
${ }^{a}$ Based on a free uroflow with voided volume of at least $150 \mathrm{ml}$

b Defined as involuntary detrusor contraction(s) with amplitude $\geq 10 \mathrm{~cm} \mathrm{H}_{2} \mathrm{O}$

${ }^{c}$ Patients classified as Schäfer 0 , I or II were considered not obstructed

d More than one sign possible in a single patient

\begin{tabular}{|c|c|}
\hline A. General patient characteristics & Median (interquartile range) \\
\hline Age (years) & $63(13)$ \\
\hline Body mass index $\left(\mathrm{kg} / \mathrm{m}^{2}\right)$ & $25.4(3.8)$ \\
\hline International prostate symptom score, IPSS & $15(11)$ \\
\hline Quality of life score on IPSS & $3(2)$ \\
\hline Serum creatinine level $(\mu \mathrm{mol} / \mathrm{l})$ & $87(22)$ \\
\hline Serum prostate specific antigen concentration $(\mu \mathrm{g} / \mathrm{l})$ & $2.1(3.7)$ \\
\hline Prostate volume on transrectal ultrasound (ml) & $40(29)$ \\
\hline Maximum flow rate $(\mathrm{ml} / \mathrm{sec})^{\mathrm{a}}$ & $12.6(8.2)$ \\
\hline Post-void residual urine $(\mathrm{ml})^{\mathrm{a}}$ & $50(122)$ \\
\hline Bladder capacity on urodynamic investigation $(\mathrm{ml})$ & 345 (279) \\
\hline B. Specific signs on intravenous urography & Number of affected men ${ }^{\mathrm{d}}(\%)$ \\
\hline Urinary tract calcifications (stones) & $17(8.5)$ \\
\hline Urinary tract dilatation (hydronephrosis) & $16(5.5)$ \\
\hline Complete filling of the ureter with contrast media & $64(31.7)$ \\
\hline Fish-hook configuration of distal ureter(s), total & $72(36.0)$ \\
\hline Unilateral & $43(21.5)$ \\
\hline Bilateral & $29(14.5)$ \\
\hline Delayed unilateral renal excretion of contrast media & $11(5.4)$ \\
\hline Delayed emptying of ureter(s) & $6(3.0)$ \\
\hline Bladder base elevation & $112(55.7)$ \\
\hline Bladder diverticula and/or trabeculation & $49(24.5)$ \\
\hline C. Specific signs at computer-urodynamic investigation & Number of affected men ${ }^{\mathrm{d}}(\%)$ \\
\hline Low bladder compliance $\left(\leq 25 \mathrm{ml} / \mathrm{cm} \mathrm{H}_{2} \mathrm{O}\right)$ & $28(14.2)$ \\
\hline Detrusor overactivity $^{\mathrm{b}}$ & $118(59.3)$ \\
\hline Detrusor overactivity incontinence & $21(10.7)$ \\
\hline Weak/very weak detrusor work (DAMPF) & $11(5.4)$ \\
\hline Benign prostatic obstruction $(\text { Schäfer nomogram })^{\mathrm{c}}$ & $83(40.9)$ \\
\hline
\end{tabular}

Table 2 Logistic regression model for the prediction of the "fish-hook" configuration of the distal ureter (uni- or bilateral)

\begin{tabular}{|c|c|c|c|c|c|}
\hline Variables & $\begin{array}{l}\text { Regression } \\
\text { coefficient }\end{array}$ & $\begin{array}{l}\text { Standard } \\
\text { error }\end{array}$ & $\begin{array}{l}\text { Odds } \\
\text { ratio }\end{array}$ & $\begin{array}{l}\text { 95\% Confidence } \\
\text { intervals }\end{array}$ & $P$ value \\
\hline Age (years) & -0.014 & 0.024 & 0.986 & $0.941-1.034$ & 0.565 \\
\hline Prostate volume $(\mathrm{ml})$ & -0.003 & 0.006 & 0.997 & $0.985-1.009$ & 0.616 \\
\hline Post-void residual urine $(\mathrm{ml})$ & 0.000 & 0.001 & 1.000 & $0.998-1.003$ & 0.835 \\
\hline Bladder capacity $(\mathrm{ml})$ & 0.001 & 0.001 & 1.001 & $0.999-1.003$ & 0.221 \\
\hline Benign prostatic obstruction (Schäfer nomogram) ${ }^{\mathrm{a}}$ & 1.291 & 0.391 & 3.638 & $1.691-7.827$ & 0.001 \\
\hline Constant $\left(\mathrm{b}_{0}\right)$ & -0.070 & 1.660 & 0.933 & & 0.966 \\
\hline \multicolumn{6}{|l|}{ Hosmer and lemeshow test: $P=0.329$} \\
\hline
\end{tabular}

Two hundred patients were available, whereas three patients without BPO did not show contrast media filling of the distal ureters and, hence, were excluded from analysis

Significant value is indicated in bold

${ }^{a}$ Reference category: non obstruction (Schäfer 0, I, II)

risks of radiation but might be conducted using MRI urography instead. However, ethical approval was not necessary at that time and therefore not obtained since all tests were considered necessary for the routine assessment of patients with BPH-LUTS in 1994.
Our aim was to evaluate the relationships between morphological and functional changes of the urinary tract and, therefore, shed light on the pathophysiology of BPHLUTS rather than to advertise IVU as a routine test for this patient group. Although the "fish-hook" configuration of 
Table 3 Distribution of patients with or without "fish-hook" ureter(s) in the absence or presence of BPO

\begin{tabular}{lll}
\hline Fish-hook ureter(s) & \multicolumn{2}{l}{ Benign prostatic obstruction } \\
\cline { 2 - 3 } & Present $^{\mathrm{b}}$ & Absent $^{\mathrm{c}}$ \\
\hline Present $^{\mathrm{a}}$ & 44 & 28 \\
Absent & 39 & 89 \\
\hline
\end{tabular}

Two hundred patients were available for evaluation of the test accuracy of this particular radiological sign; 3 patients without BPO did not show contrast media filling of the distal ureters and were excluded from calculation

a Uni- or bilateral

${ }^{b}$ Schäfer classes III-VI

c Schäfer classes 0-II

the distal ureter(s) is significantly associated with BPO, this radiological sign appears unsuitable for routine evaluation of BPO because its diagnostic value is clearly lower than that of other non-invasive tests, such as ultrasonic measurements of IPP $[19,20]$ or detrusor wall thickness [21, 22]. Nevertheless, the knowledge that the "fish-hook" sign appears in the presence of BPO might motivate physicians to evaluate for BPO whenever it is visible.

The "fish-hook" shape of the distal ureter seems to be an indirect sign of BPO and might be caused by a prostate median lobe elevating the trigone, displacing the ureteral orifice, and deforming the distal ureter. Prostate median lobe enlargement with intravesical prostatic protrusion (IPP) $>10 \mathrm{~mm}$ has been described as a significant predictor of BPO $[19,20]$. The association between IPP and BPO was first described in 2003 and, therefore, unknown and not evaluated in 1994. In contrast to IPP, bladder base elevation is not only caused by prostate median lobe but also prostate lateral lobe enlargement; this might explain why the radiological sign of the elevated bladder base (seen in $55.7 \%$ of our patients) was not an independent predictor of BPO (seen in $40.9 \%$ of our patients).

Interestingly, we failed to show significant associations between BPO and other structural alterations of the urinary tract. Bladder trabeculation showed no association with BPO or detrusor overactivity; these findings are in accordance with previous studies [23]. We also could not demonstrate any association between BPO and hydronephrosis; this stands in contrast to others who demonstrated a decreasing bladder compliance with increasing BPO grade [24] and an increasing tendency of upper urinary tract dilation with decreasing compliance [25]. Since IVU was not conducted in patients with creatinine levels $>180 \mu \mathrm{mol} / \mathrm{l}$, the number of patients with bilateral upper urinary tract dilation $(n=16)$ without impaired renal function might have been insufficient to show this relationship. Bladder stones or diverticula were considered per se as signs of BPO; these patients were treated by prostate surgery without UDI. Although bladder stones or diverticula are generally believed to be the result of BPO, only the association between bladder stones and BPO is evidence based [18].

\section{Conclusions}

The "fish-hook" configuration of the distal ureter(s) is associated with BPO. Whenever this radiological sign is detected in older men, for example during routine assessment of urolithiasis or haematuria, the patient should be evaluated for BPO and counselled accordingly.
Table 4 Comparison of clinical data in patients with or without the "fish-hook" sign of the distal ureter

Results are presented as median (interquartile range)

Significant values are indicated in bold

\begin{tabular}{lccc}
\hline Parameter & $\begin{array}{l}\text { Patients with } \\
\text { "fish-hook" ureter(s) }\end{array}$ & $\begin{array}{l}\text { Patients without } \\
\text { "fish-hook" ureter(s) }\end{array}$ & $P$ value \\
\hline Age (years) & $63.5(12.0)$ & $62.0(13.0)$ & 0.410 \\
Body mass index $\left(\mathrm{kg} / \mathrm{m}^{2}\right)$ & $25.2(3.3)$ & $25.5(4.3)$ & 0.952 \\
Serum creatinine level $(\mu \mathrm{mol} / \mathrm{l})$ & $84(21)$ & $88(21)$ & 0.234 \\
International Prostate Symptom & $15(11)$ & $14(10)$ & 0.828 \\
$\quad$ Score, IPSS 1-7 & $3(3)$ & $4(2)$ & 0.305 \\
Quality of life score, IPSS 8 & $2.8(5.9)$ & $1.8(2.8)$ & $\mathbf{0 . 0 2 8}$ \\
$\begin{array}{l}\text { Serum prostate specific antigen } \\
\text { (PSA) level (ng/ml) }\end{array}$ & $44(37)$ & $36(22)$ & $\mathbf{0 . 0 3 5}$ \\
$\begin{array}{l}\text { Prostate volume on transrectal } \\
\text { ultrasound (ml) }\end{array}$ & $49(100)$ & $48(116)$ & 0.997 \\
$\begin{array}{l}\text { Post-void residual urine (ml) } \\
\text { Maximum urinary flow rate (ml/sec) }\end{array}$ & $12.0(4.7)$ & $13.0(9.4)$ & 0.086 \\
Bladder capacity on urodynamic & $349(302)$ & $343(223)$ & 0.538 \\
$\quad$ investigation (ml) & & & \\
\hline
\end{tabular}


Acknowledgments The authors gratefully acknowledge the skilful and enthusiastic collection of the patients' data by Dr. Wibke Knöner.

Conflict of interest The authors declare no conflict of interest.

Open Access This article is distributed under the terms of the Creative Commons Attribution Noncommercial License which permits any noncommercial use, distribution, and reproduction in any medium, provided the original author(s) and source are credited.

\section{References}

1. Abrams P, Cardozo L, Fall M, Griffiths D, Rosier P, Ulmstein U, van Kerrebroeck P, Victor A, Wein A (2002) The standardisation of terminology of lower urinary tract function: report from the Standardization Sub-committee of the International Continence Society. Neurourol Urodyn 21:167-178

2. Barry MJ, Cockett AT, Holtgrewe HL, McConnell JD, Sihelnik SA, Winfield HN (1993) Relationship of symptoms of prostatism to commonly used physiological and anatomical measures of the severity of benign prostatic hyperplasia. J Urol 150:351-358

3. Bosch JL, Kranse R, van Mastrigt R, Schröder FH (1995) Reasons for the weak correlation between prostate volume and urethral resistance parameters in patients with prostatism. J Urol 153:689-693

4. Rosier PF, de la Rosette JJ (1995) Is there a correlation between prostate size and bladder-outlet obstruction? World J Urol 13:9-13

5. Girman CJ, Jacobsen SJ, Guess HA, Oesterling JE, Chute CG, Panser LA, Lieber MM (1995) Natural history of prostatism: relationship among symptoms, prostate volume and peak urinary flow rate. J Urol 153:1510-1515

6. Berry SJ, Coffey DS, Walsh PC, Ewing LL (1984) The development of human benign prostatic hyperplasia with age. J Urol 132:474-479

7. Fenter TC, Naslund MJ, Shab MB, Eaddy MT, Black T (2006) The cost of treating the 10 most prevalent diseases in men 50 years of age or older. Am J Manag Care 4(Suppl):S90-S98

8. Doubilet P, McNeil BJ, Van Houten FX, Berenberg A, Ratnofsky S, Greenes RA, Anderson JW, Mellins HZ, Abrams HL (1985) Excretory urography in current practice: evidence against overutilization. Radiology 154:607-611

9. Wasserman NF, Lapointe S, Eckmann DR, Rosel PR (1987) Assessment of prostatism: role of intravenous urography. Radiology 165:831-835

10. Stavropoulos N, Christodoulou K, Chamilos E, Karidis G, Karagiotas N, Yiannopoulos P (1988) Evaluation of patients with benign prostatic hypertrophy: IVU versus ultrasound. J R Coll Surg Edinb 33:140-142

11. Wilkinson AG, Wild SR (1992) Is pre-operative imaging of the urinary tract worthwhile in the assessment of prostatism? Br J Urol 70:53-57
12. Schäfer W (1995) Analysis of bladder-outlet function with the linearized passive urethral resistance relation, lin-PURR, and a disease-specific approach for grading obstruction: from complex to simple. World J Urol 13:47-58

13. Mulligan ME (1997) Classic radiological signs: an atlas and history, 1st edition. Informa healthcare, New York, London

14. Patel M, Tewari A, Furman J (2000) Prostatic obstruction and effects on the urinary tract. In: Narayan $\mathrm{P}$ (ed) Benign prostatic hyperplasia. Churchill livingstone, London, Edinburgh, New York, Philadelphia, St. Louis, Sydney, Toronto, pp 139-149

15. Abdel Razzak OM (2007) Ureteral anatomy. In: Smith AD, Badlani G, Bagley D, Clayman RV, Docimo SG, Jordan GH, Kavoussi CR, Lee BR, Lingerman JE, Preminger GM, Segura JW (eds) Smith's textbook of endourology, 2nd edn. BC Decker Inc, Hamilton, pp 213-216

16. Griffiths HJ (1969) Enlargement of the prostate gland. Br J Radiol 42:793

17. Costas S, Cohen IT, Van Blerk PJ (1972) Benign prostatic enlargement and the fish-hook sign of the ureter. S Afr Med J 46:1721-1723

18. Douenias R, Rich M, Badlani G, Mazor D, Smith A (1991) Predisposing factors in bladder calculi. Review of 100 cases. Urology 37:240-243

19. Chia SJ, Heng CT, Chan SP, Foo KT (2003) Correlation of intravesical prostatic protrusion with bladder outlet obstruction. BJU Int 91:371-374

20. Lim KB, Ho H, Foo KT, Wong MY, Fook-Chong S (2006) Comparison of intravesical prostatic protrusion, prostate volume and serum prostatic-specific antigen in the evaluation of bladder outlet obstruction. Int J Urol 13:1509-1513

21. Oelke M, Höfner K, Wiese B, Grünewald V, Jonas U (2002) Increase in detrusor wall thickness indicates bladder outlet obstruction (BOO) in men. World J Urol 19:443-452

22. Oelke M, Höfner K, Jonas U, de la Rosette JJ, Ubbink DT, Wijkstra H (2007) Diagnostic accuracy of noninvasive tests to evaluate bladder outlet obstruction in men: detrusor wall thickness, uroflowmetry, postvoid residual urine, and prostate volume. Eur Urol 52:827-835

23. el Din KE, de Wildt MJ, Rosier PF, Wijkstra H, Debruyne FM, de la Rosette JJ (1996) The correlation between urodynamic and cystoscopic findings in elderly men with voiding complaints. J Urol 155:1018-1022

24. Madersbacher S, Pycha A, Klingler CH, Mian C, Djavan B, Stulnig T, Marberger M (1999) Interrelationships of bladder compliance with age, detrusor instability, and obstruction in elderly men with lower urinary tract symptoms. Neurourol Urodyn 18:3-15

25. Comiter CV, Sullivan MP, Schacterle RS, Cohen LH, Yalla SV (1997) Urodynamic risk factors for renal dysfunction in men with obstructive and nonobstructive voiding dysfunction. J Urol 158:181-185 